\title{
Environmental Crisis and the Role of Media
}

\author{
Vineet Kaul \\ Scholar, DA-IICT ( Dhirubhai Ambani Institute of Information, Communication \& Technology) University \\ Gandhinagar, Gujarat, India
}

\begin{abstract}
Environmental concerns are increasingly relevant to everyone, and an informed public is a critical ingredient in the necessary practical steps and policy changes needed to alleviate the developing crisis. Environmental issues have become more entwined as communication technologies proliferate. The aim of this paper is to contribute to the understanding of the media dynamics with reference to the environmental issues alarmingly challenging to human continued survival. The scientists are disturbed for its insecurity, mis-governance, degradation, management and conservation which have gradually come to capture the centre stage. At this juncture, the role of media becomes pertinent in spreading environmental awareness and making the public aware of the formidable crisis looming large over our heads. Although environmental problems are typically discovered by scientists but it is media that often play a central role in disseminating information, influencing people's attitude and promoting public awareness. Media are the cornerstone of any public opinion and acts as a catalyst for change.
\end{abstract}

The ultimate objective of this paper is to find the most decisive factors in creating awareness since this is the first step in developing effective campaigns to promote and protect the integrity of the natural environment for prosperity amongst the population. This paper is an attempt to review the meaning of environment education, its aims and objectives, and ways of promoting environmental awareness in the society.

A major challenge to environmental reporting is how to convey complex concepts and impart a sense of the urgency of these challenges in a way that engages the reader.The paper also explores the evolving field of environmental journalism which prefers objectivity over advocacy (Sachsman, 2006:112) with utmost professionalism and scientific information. There is a need for more accurate and unbiased reporting in framing and forming some of the main determinants of public opinion. Sociologist Gaye Tuchman(1978) argues that the news reconstruct social world and are a window to the world, determining, what we want to know, what we have to know and what we should know.

Keywords: environment, degradation, conservation, public awareness, journalism, media

\section{Introduction}

The unprecedented environmental changes may be one of the greatest threats facing the planet and have the potential to affect all of earth's inhabitants. This could alter life in many arcane and unpredictable ways as it is being closely observed, predicted, studied, analyzed and adapted to become scientific discovery. Environmental issues are today no longer confined to geography and allied disciplines but have also drawn the attention of common people as environmental degradation has assumed global dimension and even threatening the very existence and survival of mankind (Singh 2000:8). To meet the environmental challenges of $21^{\text {st }}$ century, a successful environmental communication is paramount for responsible actions by the community. Environment constitutes an inseparable part of our life as throughout human existence, man has found himself in one way or the other in a relationship with his environment in an effort to find shelter, food, medicine, and other necessities of life. It will be a mistake to assume that there is a sudden deterioration of environment and now over night it has become a burning issue the world over. Nay, for centuries the unwise and unbridled exploitation of natural resources of Earth has resulted in boiler-stress and pressure on natural resources and quality of life without any dither and demur. Scientists have been warning for decades that human actions are pushing life on our shared planet toward mass extinction. Recent studies indicate 
that public concern about the grim environmental situation that has been on the increase since the mid1980s (see Young 1990). The environment is becoming complex with ramifications for our planet's future and demands urgent action with a multipronged approach.

Many contemporary social scientists have emphasized the role of media as one of the key feature of "high modernity" (Giddens, 1991). Most people will not learn from the cautious lexicon in scientific journals but rather from media. Increasingly, it is the media's responsibility to translate complex, scientific concepts to the' lay audience". There is a necessity of bringing the media to play a more active role in the process of bringing about the much needed environmental awareness and consciousness which will ultimately lead to environmental change. This is going to be a stiff challenge when so to say media are bereft of reporters, journalists and specialists and still they are promoting public awareness.

Today at the dawn of twenty first century humanity faces double daunting environmental challenges which grow greater socially, technologically and financially. It seems that the prognoses of climatologists become more urgent and the chasm between what needs to be done and what is actually being done gets widened. Environmental bankruptcy is now as big as the world and as local as your backyard and despite consecrated efforts to establish a balance between the protection of environment and quality of life, the degradation of environment continue accelerating and unabated the worldwide. This is an inconvenient truth which goes underreported despite the fact that developing countries are most vulnerable to severe insecurity threats by climate variability and change. Many people don't pay much attention to environmental problems because they don't understand how the problem would affect them or their lifestyle. Admittedly, it is slow moving, not very attractive, complex to explain and steeped in scientific jargon. Information dissemination is difficult to manage and it fails to capture public imagination unless there is a crisis. Our planet is poised at the brink of a severe environmental crisis. Current environmental problems make us vulnerable to disasters and tragedies, now and in the future. We are in a state of planetary emergency, with environmental problems piling up high around us. Unless we address the various issues prudently and sagaciously we are surely a gone goose. Today's environmental challenges are staggering in their severity and scope and require urgent attention if zero environmental impact is to be achieved.

Social scientists have devoted considerable study and concluded that unless the environment is protected, the existence of life of future generation on the planet Earth would eventually be impossible. In modern society environmental concern is widespread and will remain so till we address its major determinants even to a man in the street. The concept of sustainable development needs to be elucidated by policy makers, communications professionals, academics and journalists. Being merely aware of environmental issues and problems is not an accomplishment; we need to see positive influence on people's attitude, action and behavior for conservation, protection and the management of environment. Every person, organization and institution has an obligation and duty to protect it. It is, therefore, imperative to make public aware of the catastrophic impact of the environmental decay, if not retorted and reformative measures undertaken would result in the extinction of life.

Most of the ordinary people think that there are so many technologically literate scientists to tackle these problems and then it is government's responsibility to deal with it. It is a wrong thinking and no science and technology or political leadership can ever deliver sustainable development. The initial euphoria is dissipated and many environmental luminaries have adopted blasé attitude and resigned to fate. This does not augure well for the vast majority of the world's people.

In the rapidly changing information-based media society, media literacy is becoming increasingly important. The communication technologies have dramatically changed the media landscape and taken mankind into a new era. In this turbulent era, the media has played a significant role in shaping popular views on environment.

Most of the ordinary people think that there are so many technologically literate scientists to tackle these problems and then it is government's responsibility to deal with it. It is a wrong thinking and no science and technology or political leadership can ever deliver sustainable development. The initial euphoria is dissipated and many environmental luminaries have adopted blasé attitude and resigned to fate. This does 
not augur well for the vast majority of the world's people.

Nwogbunyama (2010:76) adds that "the media are interwoven with the society that neither of them can exist without the other. In this modern knowledgesociety, media potentially plays the role of facilitator of development, disseminator of information, and an agent of change. One of the roles of media is to educate society, creating its environmental consciousness and thereby providing space for dialogue and mediated discourses, unique conduit for people to communicate their own perspective and demands to the rest of the world. Subsequently, civil society, research institutions and government agencies can lobby, find technical solution or enact regulations to bring positive changes. It is an incontrovertible fact that the media mounts considerable influence over public perception of environmental groups, corporations and the government. The media can be persuaded, cajoled, forced into taking a much more responsible position when it comes to relaying facts about environmental change to its audience. The role of media in the dissemination of information to the public on issues of grave importance cannot be overstressed. News publications and journals, television and radio are the source of information to the public on environmental issues.

The power of media lays on the facts that they are widespread and shape, or even wield public opinion. Science public understanding of the issue relies heavily on media coverage, media are indispensable. As the media become more market-driven and proven to be a key contributor in shaping, affecting science and policy discourse, public understanding and action of various issues of environment, technology and risk (Weingart et al. 2000). Scientists emphatically assert that media has to play a critically pertinent role to sensitize people, reduce ecological footprints and adopt green technologies (Barr, 2003, Fahlquist, 2008, Miller et al, 2010) without losing shred of impartiality and balance. In this turbulent era, the media has played a significant role in shaping popular views on environment. It is a complex and multidimensional task and primary responsibility of journalists and reporters to be proactive and determined with accurate, un-biased with transparent agenda.

\section{Environmental Awareness through Media}

Everyone has a right to live in an environment that is healthy and ecologically balanced. Environmental awareness/ consciousness has a broad connotation and has a strategic communication process to enhance the knowledge of environment, keep people up to date about catastrophic impacts of human development and help them to know about sustainable development. Public awareness about environment is at a stage on infancy and we have to instill and inculcate awareness to protect and conserve for sustainable development (Hens, 1996). A large proportion of rural populations in developing countries are not able to read or write, even in their local languages. Studies indicate that radio broadcasts are effective in reaching local communities with targeted messages. The use of dramas, talk shows, stories, and other media tools can play a critical role in public awareness campaigns.

Incomplete knowledge often leads to misconception and never addressed in their full range and seriousness. For the sake of our world, clearly environmental awareness plays critical role for creating interest in environment not only for present generation but for future as well. Media is a powerful tool that can foster development and can play a strategic role in raising environmental awareness, channeling environmental information and inspiring environmental action without falling into scaremongering or lazy anecdotes (Novo 2003 pp.222) .Media representations are framing environmental issues for policy, politics, and the public perceptions, attitudes, intentions, and behaviors, in turn, often link back through mass media into ongoing formulations of environmental governance. Media need to play an indispensable environmental watchdog to lapdog to guard- dog role in supervising wrongdoers and communicating with the public. Media can foster environmental awareness and encourage people's participation in issues of its conservation. It has the potential to create community forums on environmental issues. Local projects, national trends and the latest communication technologies all can set the pace for a better understanding of the environment.

The last two decades of the $20^{\text {th }}$ century have witnessed a burgeoning global environmental awakening to the kind of doom and gloom that we are told will affect us all. There are interminable discussions on the nature and magnitude of 
environmental problems by liberals, progressives, and environmentalists. $21^{\text {st }}$ century is known as the most developed period of time immemorial, yet we have to achieve a lot for ultimate betterment, but there is happening a severe aggravation of environmental degradation. The question of environmental misgovernanve, insecurity, degradation, conservation and management has perhaps gradually arrived to dominate the centre stage. Environment is no more an option for the government and the governed but it is an imperative need that must be placed at the centre of economic and political decision making. If we fail to protect the environment properly, we could at best be at best make life unbearable for millions of people and at worst head towards obliteration.

In the preceding two decades, environment has attracted the attention of decision makers, scientists and even laymen in many parts of the world. As environmental problems which are both complex and multidimensional escalate day by day and many national and international reports, conferences, campaigns, organizations have frequently come up for protecting and banning activities that endanger environment. Academic debates over what constitutes "the environment "were never argued as fervently as they are today. At this paradoxical juncture it is now a collective responsibility of all stakeholders: governments, scientists, media organisations, development partners, and indeed the general public to strengthen the interdependent and mutually reinforcing elusive sustainable development at the local, national and global levels. We at this hour need careful, longer-than-bite-size reporting as it involves probabilistic science, labyrinthine laws, grandstanding politicians, speculative economics and the complex interplay of individuals and societies. It is difficult for citizens to learn from the cautious lexicon in technical journals and in developing countries it is covered in pedantic manner by local media to understand policies and their implications. This is an emergency and emergency situations need emergency actions (UNEP 2007). According to EPA (1998) annual report, environmental protection requires equipping its beneficiaries and authorities with comprehensive information for decision making about recent problems, challenging the specific countries and the world at large. It has, therefore, become important to promote a higher level of environmental awareness among the population to avoid doomsday. It is not a sprint but a marathon race and every country must be an important $\operatorname{cog}$ of the solution. The main tool for creating true awareness at macro level is by far, the media.

High public trust in the media is an important factor influencing effectiveness of the mass media in public opinion formation. The media play a significant role in selecting, transforming and transmitting environmental constructions in modern society, although environmental problems are not structured as priority issues in both public and media agendas. The study indicates the lack of understandable and accurate environmental information in the mass media .Currently, media interest in the notion is limited; media outlets mainly cover meetings or publicize information received from the authorities, pressure groups, civil societies and project proponents. At present, very few reporters or editors have much of a background in environmental issues and that makes them reluctant to write or cover articles on the environment. Both traditional and citizen centric media are important part and parcel in the climate information cycle as information disseminators, mobilizes, translators, environmental scanners, platforms for debate and fora for intercultural learning .Why do current media coverage focus merely on the negative impacts of climate change rather than on ways to deal with it? The media have to play an indispensable environmental watchdog role in supervising wrongdoers and communicating with the public. Environmental reporting has been inconsistent and unsystematic and that reporters need to work closely with major environmental stakeholders such as scientists, academia, NGOs and others to expand their source of reliable information (Yang, 2008). It is, therefore; no surprise that, despite sporadic efforts across the continent, the quality and quantity of coverage of the environment still depend to a great degree on the personal interest and commitment of journalists, editors and owners. Local issues are dominating over global issues in public and media environmental discourses. Media should improve reporting on urgent global environmental issues disseminating updated scientific information and sustaining public discourse on global environmental situation.

Why should media outlets not dedicate a column to environmental issues, including approved EIA projects? The story does not need to appear on the front page of the paper (a common excuse for not 
carrying or covering an environmental issue), it can be somewhere inside the paper. Undoubtedly, media houses, development partners, foundations and international NGOs should enhance the capacities and capabilities of reporters and journalists in the area of environmental management for public awareness and involvement. Media could play a double role: as overseers and as creators of awareness and related environmental issues.

.Environmental macro/micro issues need to properly researched/reviewed to stitch spaces of environmental science, governance, and daily life together. Although media interventions seek to enhance understanding of complex and dynamic human-environment interactions, vague and decontextualized reporting instead can enhance bewilderment.

Many studies have discovered that TV and daily newspapers are the primary source to learn about science. Media are considered a subset, publishers, editors, journalists and others who constitute the communications industry and profession, and cover a range of environmental issues. Interactions between climate science, policy, media and the public are complex and dynamic. It is clear that science and policy shape media reporting and public understanding, however, it is also true that journalism and public concern shape ongoing climate science and policy decisions and activities. While journalists have consistently viewed their role as one of information dissemination rather than education, the distinction between these roles becomes blurred in practice. Many news editors and producers consider coverage of environmental issues an option instead of an obligation. Environmental issues don't make headlines unless they turn into disasters. It's necessary to guard against the trend of succumbing entirely to market forces. However, its developments have both pros and cons and raise a few questions: Who becomes empowered and disempowered through particular media practices? How do media address or efface their environmental impacts and how can activists and academics develop new imaginaries in response? How do the media frame 'expert' counter expert and lay-public definitions of environment risk? What role do environmental pressure groups like Greenpeace, or, eco-warriors and green -guerrillas play in shaping what gets covered and how? Does the media's emphasis on spectacular events at the expense of issue-sensitive reporting exacerbate the public tendency to overestimate the sudden risk and underestimate chronic long term ones? In order to explore the many noteworthy confluences of media and environment, what role do the media play in influencing personal, national, and international action to address climate change? How much has the media covered climate change, and what is driving changes in that coverage? How do climate change stories come to be reported, and who gets cited as legitimate sources in those stories? What influence do the media play in forming public opinion?

The media should also avoid doing too much anniversary or campaign journalism, which often results in redundant reporting on a specific issue or event. Environmental reporters need to be better trained. Environmental reporting should be more incisive and more appealing to the younger audiences, a target group that is essential for the media to sustain itself and exert influence in the future.

Lastly, reporters need to work closely with such major environmental stakeholders as the NGOs, to expand their sources of reliable information. Additionally, the flourishment of internet forums and blogs has created another important information source. This new network has made it possible for a tiny local story to become a nationwide sensation overnight.

Greater media attention, effective government initiatives and increased affluence have contributed immensely to environmental awareness. Sustainable growth is no longer everyone's responsibility but our own. As the economy continues to grow, we will face an increasing range of environmental challenges. The government, media, NGOs, schools, businesses and the people themselves have always been, and will continue to be, the driving forces of this momentum. The media, despite its significant role in this process, cannot claim the credit alone.

Environmental issues are given prominence in the media and scientific circles. There have been innumerable changes the way people related to the environment with a paradigm shift. Media as a force play the instrumental role in modern societies of facilitator of development, disseminator of information, and being an agent of change in alerting people about damages and legal obligations. Media play an influential role both as a precautionary tool to warn against potential environmental threats and, at 
the same time, suggesting corrective solutions as well as being a monitoring tool. New approach and structure will help understand how environmental issues are constructed, contested, understood across a range of media platforms and acted upon. Today, people have wide selection of media which can have impact on their beliefs, attitudes, values and knowledge. Yet, the importance of mediated communication in understanding the environment appears not to be getting through general public because of superficially researched and poorly written environmental issues. Scholars have lamented the state of fragmentation in communication scholarship for it undermines its consolidation as a distinct and coherent field of study. Through time, media coverage has proven to be a key contributor - among a number of factors - that have shaped and affected science and policy discourse as well as public understanding and action. Our goal is environmental sustainability which rests on non-negotiable planetary preconditions (Rocksrorm et al 2009:4). That set limits on how much earth can give and absorb.

There are perennial difficulties in traversing the dynamic terrain of media reporting and the environment. Among the key questions to address are: What is the relationship between nature and society? What role do the media play in influencing personal, national, and international action to address environmental degradation? How media reports influence the spectrum of possibilities for different forms of environmental governance? How much has the media covered climate change, and what is driving changes in that coverage? How do climate change stories come to be reported, and who gets cited as legitimate sources in those stories? What influence do the media play in forming public opinion? What factors trigger particular environmental stories to make their way into the headlines while others are ignored? How do issue attention cycles operate? And how do some actors seek to keep issues off the agenda? What factors trigger particular environmental stories to make their way into the headlines while others are ignored? How do issue attention cycles operate? And how do some actors seek to keep issues off the agenda? These are not rhetorical questions. Media have to prepare complicated stories involving abstract and probabilistic science, labyrinthine laws, speculative economics and the complex interplay of individuals and societies (Stocking and Leonard 1990). This article proposes some practical ways to increase public understanding of the issues, and stresses the key role the media should play in this process

The media have, after all, assumed the status of supreme arbiter of significance in our society and earned prestige and currency. Today, various types of media enable people all over the world to interact and learn from each other at a tremendous pace. Media representations have encompassed a wide range of activities and modes of communication. From performance art, plays, and poetry to news and debate, media portrayals have drawn on narratives, arguments, allusions and reports to communicate various facets of the issue. Media are generally considered a subset of these broader media practices and defined as the publishers, editors, journalists and others who constitute the communications industry and profession, and who disseminate information, largely through newspapers, magazines, television, radio and the internet. There have been many studies over the last two decades that have examined how media have covered a range of environmental issues. In this new "age", known now as the Anthropocene, we are entering a new moral universe, a universe in which the old parameters of meaning are shifting.

Media are most commonly used to influence public opinion on environmental issues. There are many qualitative and quantitative analyses of media coverage of environmental issues and some have shown rise and fall of media attention while others focused on the reasons behind the cyclical nature attention. (Trumbo, 1996; McComas and Shanahan, 1999; Weingart et al., 2000; Brossard et al., 2004; O'Brien, 2006). They found that exposure to the media was positively correlated with the level of concern over environmental issues but the topics of attention vary month to month.

Mazur and Lee (1993) indicated that the level of public concern about environmental issues tends to be affected by the amount of media attention they receive, rather than by the substantive content of the news reports. The pervasive force of mass media is likely to expedite its evolution. Has the era of modern mass media introduced significant changes? What is the impact of mass media on people's attitudes? What is its role in affecting attitudinal transition towards environmentalism? How could media play a fruitful role in promoting environmental awareness? Such questions become pertinent since, not only does mass 
media serve as a medium for socio-economic and psychological development, but it can also play a vital role in promoting cultural and environmental integrity.

\section{Environmental Education}

The importance and significance of the environmental education as one of today's accentuated assignment is unquestionable. The history of environmental education reveals that we can change behavior by making human beings more knowledgeable about the environment and its associated issues. Environmental education is a multidisciplinary process and can be a trans-disciplinary venture (Krasny and Dillon 2013). The aim of environmental education is to enable people to understand the complexities of the environment and the need for nations to adapt and pursue their activities and development in ways which is harmonious with the environment. The steadily deteriorating state of the environment has emphasized the need for environmental education. Obviously a powerful vehicle bringing about change, a panacea of all evils and a potent weapon for prevention plays a central role in the society. Environmental education is a way of creating knowledge, understanding, values, attitudes, skills, abilities and awareness among individuals and social groups towards the environment protection. Environmental education is an attempt to reorient education so that environmental competence is restored as one of its basic aims along with personal and social competence. It is not just a subject of education but an expansion of its whole philosophy recognizing our environment as continuous with ourselves and in need of the same case and understanding as we give to our personal and social well being (Smyth, 1995). This calls for a radical change in the way we think, live and work. Action can be taken in a variety of areas to increase environmental awareness and education. Some of these categories are: use of the media, awareness raising campaigns, incorporation of environmental issues in mainstream education, increasing awareness and education in target groups and encouragement of public participation in environmental matters.

World educators and environment specialists have repeatedly pointed out that a solution to environmental crisis will require an environmental awareness and its proper understanding which should be deeply rooted in the education system at all levels of school education (Shukla, 2001). The existing curricula at primary, secondary and college levels provide a lot of opportunities to make the students aware of environment. The integration of environmental education is possible if teachers have a will to introduce it in a quite natural way while teaching different curricular areas at primary, secondary and higher education level. In this present context the need for studying the environment awareness of secondary school student is a must. It is an essential need for each individual to develop an awareness of protection and preservation towards environment. Our environment is threatened due to many hazards. Air, water and soil pollution is on the increase. Degradation of environment results in many problems. Therefore, there is a great need to protect and preserve our environment. Action can be taken in a variety of areas to inc It must offer both cognitive skills (related to imparting both technical and theoretical knowledge) and emotional stimuli, which are concerned with the formation of values, knowledge, skill, attitudes, motivation and commitment to work individually and collectively and--subsequently--behavior

(Skanavis

2004).Environmental education plays a key role in sensitizing people of the need and significance of any such programs, which are carried out to address environmental problems confronting them. Environmental education increases public consciousness and knowledge of environmental issues and challenges. People profit, through environmental education, by gaining an understanding of how their individual actions affect the environment, acquiring skills that they can use to evaluate various sides of issues, and becoming better equipped to make informed decisions.

Environmental education also gives people a deeper understanding of the environment, inspiring them to take personal responsibility for its conservation and restoration (Mukharji, 2004). Environmental education also helps bring forth the traditional solution to address the modern environmental crisis by discovering the time-honored connection between nature and culture. This is particularly true in a traditional society where environmental consciousness is the upshot of a culture of associating various aspects of environment to a sacred space. The tremendous signification of the message of environmental education for the survival of man has made the relatively new academic discipline to attract great attention. The profundity of such a link, on 
which people's environmental consciousness is established, stirs tremendous awe and reverence for the environment and hence its preservation. An educated public can be one of the most powerful weapons in the world's battle against harm to the environment. The ways that the public can assist in enforcement efforts are as numerous as the potential approaches for increasing public awareness. Caring for the environment will not require one to become an environmental activist, but just to know more about one's environment. Public should understand about the fact that if we degrade our environment, we are harming ourselves.

Mass media is an unfamiliar expression of a familiar medium of communication that was dominant in Bhutan, particularly in the form of radio and print media prior to the advent of more invasive forms of media such as TV and the internet. Even though, mass media has been present in the country for nearly five decades, it is not until the turn of new millennium, with increased accessibility to other pervasive forms of media, that it is able to gain fresh momentum and significance. So, the concept of mass media in the country is Media and Public Culture as old as it is new. Janowitz (1969) describes mass communications as comprising specialized institutions employing technological devices such as press, radio, film, etc., to circulate important subjects to large, diverse, and widely distributed audiences. According to V. K. Narayana Menon (1981) (cited by S.P. Alahari, 1997), the notion of individuality is lost in the word 'mass' and various forms of media such as radio, television, newspaper, etc., report events intended for such an enormous number of listeners, viewers, and readers. The advances in telecommunication networks have revolutionized the function of mass media to serve wider coverage at a faster pace worldwide. This has provided an enabling environment for media in the new era to achieve its ultimate aim of reaching to a very large audience in Bhutan. Mass communication, therefore, plays a crucial role in connecting the world to an individual, and provides opportunity for the individual to communicate with a wider audience. However, the downside of mass media communication, as national and international media ownership is more likely to be influenced by a few, is in its difficulty to maintain neutrality to what is being shared through different modes of public communications (McDonald, 2004; Ura, 2006). A classic example of the case in point can be illustrated by referring to often one-sided picture presented by mainstream western media of events unfolding in Balkan in 1999 and of the American war on Iraq (Kuensel, May, 1999a; BBC news, 2005). It is reported by S.P. Alahari (1997), however, that one of the greatest concerns of many communication scholars in not so much the effect of mass media on people in general, but the potential function of mass media for bringing desirable social change and for achieving the developmental goals of nations. Several scholars set the stage on the dynamics of development and the role of mass media in achieving developmental goals. Daniel Lerner (1958) emphasized the relationship between communication, urbanization, and modernization by considering that urbanization is an important step towards

\section{Environmental Journalism and its Limitations}

Environmental journalism started taking off from the 1970s and made its ways into many different types of specialized media. An environmental journalist of merit needs to be a journalist, a scientist, and an environmentalist. The environmental issues have become more complex, challenging, demanding, crucial and global than in the past. For journalists working on environmental "beat" with risk-type subjects, it is difficult to recreate, visualize and portray since they involve abstract and probabilistic science, labyrinthine laws, grandstanding politicians, speculative economics and the complex interplay of individuals and societies (Stocking and Leonard, 1990). In developing countries, most journalists are generalists, and have little training in science or the environment and are uncomfortable covering environmental related issues Furthermore, one must also assess journalists' challenges including news traditions, advertiser pressure, management policy, finance, reporting repercussions, deadlines, space, one-source stories, complexity, reliability, political struggles, technological shift and journalist's education. Environmental journalists normally dwell up on problems rather than writing stories to help the public to understand research or complex issues. The global complexity of environmental crisis demands a responsible attitude from reporters and journalists based on documentation, consequences, actors involved, background narrative, and analysis of facts and situation of events. Journalists must increasingly understand the substantive, sophisticated dimensions of the fields on which they report- from medical and 
environment science, to economic and financial disciplines, to legal and constitutional matters. The fundamental difficulty for environment reporting is that its specificity is not recognized or promoted. Yang (2004) observed that there was a tendency among journalists to present news "in a monocausal frame that fails to encompass the multifacetedness and interconnectedness of the environmental problem". One problem arising from this simplification process that A.G.Anderson(2002) has notice is "that by simplifying complex scientific information one inevitably distorts it" (p 7)

Today, coverage of environmental issues can be classified as risk reporting or science journalism or environmental communication (Rademakers, 2004) .Editors often do not recognize the news values of these environmentally responsible journalists stories. Environmental journalism has often been a poor cousin and this is evident through negligible media coverage of environmental issues due to inherent constraint of their work. However, now we have started seeing the changing climate taking roots in media landscape though for reporters, environmental journalism is one of the most extensive and complex genres of journalism which require experience, nuance and utmost professionalism without confusing this with environmental activism (Victor Bachetta, 2002). For all environmental reporters and journalists it is imperative in general to be innately curious, creative, and persistent in order to get the job done and they seriously act upon.

Environmental journalism" means mass media coverage by a journalist about the environment for a general audience. The purpose of environmental journalism is to inform the public so they make the best decisions in a democracy. If we retrospect, environmental journalism started taking off from the 1970s donning the role of journalist, scientist and environmentalist. Prior to 1969-1970 newspapers were slow to play much part in recognizing "environmentalism" (Pryor, 1972; Sellers and Jones, 1973; Witt, 1974) and reporters and journalists had trouble with both the substance and the style of environmentalism. This was an era of a journalism of uncertainty (Schoenfeld, 1980). Today, reporters, editors and journalists have entered an environmental decade as the environmental problems are accelerating day by day. The press is trying to adopt a holistic environmental lexicon to address questions related to environmental issues more empirically and without diluting coverage.

The environmental problems society faces today are at a scale and magnitude unlike those faced in the past. Environmental journalists have a challenging task before them as environment demands keener and deeper reporting, discussion techniques thorough background investigation, translation of technical information, and consideration of larger issues like future consequences. What they translate for the public is a language full of possibilities. The presentation of information, ideas, and outcomes is a significant assignment. Environmental journalists can have an influence on society, and consequently make significant impacts on the future. As Gore (1991) stated, "The media have a responsibility to inform and to educate, to tell us not only what is happening today but also why it is happening and what it will mean to us - today and tomorrow" (p. 183).

The beat of journalist covering environment is extremely challenging and innately complex because it encompasses the topic of many other beats like law, business, and politics (Bowman, 1978; Detjen, 1997; Friedman, 1991b; Sachsman, 1999; Schoenfeld, (1980); Wilson, 2000). As Sandman, Sachsman, Greenberg, and Gochfield (1987) stated, "The most fundamental problem characteristic of environmental news reporting is that environmental risk information is neither easy to obtain nor easy to understand" ( $p$. xii). Besides there are some constraints, possibly inherent in the press as an institution that limits its role in the incipient construction of some social problems. Where does one draw the line between science and environmental reporting, or between political and environmental reporting? (p. 19)

However, for journalists this is an obligation of ethical and social values and they should regularly report their new findings in media which are concerted, consistent and informed. Scientists and journalists have to work in tandem to create a solid scientific foundation to increase the people's awareness, attitude, and behavior and mobilize participation in protection and conservation activities. To qualify as "environmental," a story has to encompass in a positive way at least one of the key concepts espoused by early environmental claimsmakers, Johnstone et al. (1976), following the lead of Cohen (1963), had found a clear distinction in role definition between "neutral" journalists and 
"participant" journalists. One adheres to a "nothing but the truth" which is verified news without reflecting personal values and the other ones are committed to "whole truth" approach which can seek out ramifications so that all "relevant" information is presented. The first is the traditional and pristine professional view that those in the press are strictly reporters, passive and objective recorders of "real" events from which readers should draw their own inferences and conclusions. The second, of course, advocates that the press should play an active role in interpretation and in constructing social reality for readers. Environmental reporters and journalists have helped forge not only an environmental consciousness, but also a political activism that pressures the governments for change. Together, they share a professional commitment to reporting or doing a story on environmental degradation and raising public awareness of the endangered ecological resources. Tapping into the Internet conceivably help journalists give a more balanced, complete and widely conceivable accounting of environmental degradation. Coverage of environment is not only reporting current practices but what kind of repercussions they will have in social and political realm. Ironically, scientists and other experts often disagree about the facts, making it difficult for journalists to judge the testimony (Corner and Richardson, 1993)

Today, environmental journalism is in its nascent stage in comparison to the broader news media .But ironically the safety of journalists who cover environmental issues is subject to debate. Intimidation, threats, physical violence and sometimes even murder by local mafia are exposed to potentially devastating forces. In recent years, a multilateral effort to encourage journalists to use news columns to influence the social reality cover notoriously difficult environmental issues has been underway. Though many journalists find technical environment stories/ jargons/ technical language difficult to understand but with academic or professional training and development, right information and support, they can be equipped in developing well articulated environmental stories. This will help the populace to establish linkages between various aspects of our lives and environment. Journalists have to be pro-active in reporting well-researched and presented stories, articles and programs to bring about desired changes. They do function with some independence in their news columns, identifying social problems and some solutions to them.

Critics say that journalists under-report the broader aspects of environmental problems. One possible reason could be that they don't have an education or background in environmental issues or science (Anderson, 1997; Detjen, Fico, Li and Kim, 2000; Friedman, 1991a) or, as Nelkin (1995) said, "Journalists might avoid substantive questions because they are unable to evaluate what they are told." Friedman (1991a) noted that some journalists couldn't interpret environmental pollution data and have to ask sources (p. 40). In addition, many environmental journalists, like journalists generally, work in newsrooms in which higher-level constraints and limitations influence the formation of a “journalist environmental agenda (Detjen et al, 2000).

The need to create the interest to sell newspapers to readers is another challenge for journalists covering science and the environment (Gee, 2000; Goodfield, 1981). Journalists may feel the need to find the new all the time, which is another challenge since environmental issues are chronic, long lasting issues (Anderson, 1997). Editors usually evaluate news stories based on basis of color and excitement (Nelkin, 1995). All these reasons exemplify the challenge that journalists face covering their beat.

Most media do not have a full-time environmental reporter on staff as they think that it is not a prime beat which can make head-line news. Business communities bitterly oppose protection of environment because they do not want to be told how to run their companies either by government or treeloving hippie environmentalists. This tug-of-war becomes touchy for journalists and they face a hostile environment. Likewise there are many challenges to environmental journalists including news traditions, advertiser pressure, management policy, editors, space, time, finances, complexity of the environment beat, the relationships the environment has with other beats, translation of scientific or technical information, reporting repercussions, the uncertainty of the environment, disagreement between sources on the facts, the need to find the new, competition with other news, education of journalists who report about the environment, and the advocate versus objective role on the environmental beat. Luckily, as well as the 39 criticisms and challenges found in the scholarship, 
there are many tips and suggestions to assist in improving environmental journalism.

In order to surmount the myriad challenges of environmental reporting and to improve the quality, journalists should use the best sources to understand the needs of particular audience. Beat should be without any pressure of ideology so as to educate, expose and encourage. Science and environmental journalists should work in tandem without making any assumptions and try to make complex issues comprehensible to fit daily environment. Scientific information should be translated and technical matters lucidly explained by journalists.

\section{Conclusion}

Environment has become an important subject of international debate. The life threatening consequences of environmental degradation are becoming increasingly exposed. Thus any acts of environmental degradation are very often a subject of media coverage. Media now give serious attention to various issues as biggest source of information for the public. The complexities of environmental issues require journalists to transform technical jargons into layman's language to avoid misinterpretations,

The media's role in environmental education is important because it is through newspapers, magazines, radio, and television that people gain awareness. Awareness is simply a step in EE.. It has a vast delivery span given the fact it can reach audiences in homes, schools and public places .With proper conduction, media can offer us good communication tools that can be used as educational aids to reduce the gap between scientific knowledge and civic awareness.

As Allen (2001) says; "Scientists and journalists have had plenty of positive interactions. Yet despite the idealistic motivations of scientists and professional journalists, chaos and hard feelings sometimes characterize the interactions between them. Such discord is largely the result of a clash of two cultures, science and the newsroom. Framed simply, science is the world of labs, publications, peer review, and acceptance according to the values and norms of science. Journalism's task is to inform the public speedily, to detail history on the run."
Moving towards the goal of sustainability requires fundamental changes in human attitudes and behaviour. Progress in this direction is thus critically dependent on education and public awareness. The concept of sustainable development - as this document suggests - is not a simple one, and there is no road map to prescribe how we should proceed. Yet time is short, and we are called upon to act without delay. We must move ahead now, in a spirit of exploration and experimentation and with the broadest possible range of partners, so as to contribute through education to correcting trends that place in jeopardy our common future.

\section{References:}

Alahari, S. Prasad (1997) Modernism, Alienation and Media Behaviour, Chennai: T.R. Publication

Allen, William. 2001. A news media perspective on environmental communication. Bioscience, Vol. 51, 1ssue 4, p289, 3p.

Anderson, A. (1997). Media, culture and the environment. New Brunswick, New Jersey: Rutgers University Press.

Anderson, A,G.(20020. The media politics of oil spills. Spill Science \& Technology Bulletin, 7-15

Anthony Giddens (1991) The consequences of modernity, Polity Press, Cambridge - James Arvanitakis

Barr, S. (2003). Strategies for sustainability: Citizens and responsible environmental behavior Area, 35: 227-240.

B B C News , 2005 . News website 's most read stories of 2005

Bowman, J.S. (1978). American daily newspapers and the environment. The Journal of Environmental Education, 10(1), 2-11.

Brossard, D., Shanahan, J., McComas, K., 2004. Are issue-cycles culturally constructed? A comparison of French and American coverage of global climate change. Mass Communication and Society 7 (3), 359-377. 
Cohen,Bernard C.1963.The Press and Foreign Policy.Princeton,NJ:Princeton University Press

Corner, J\&Richardson,K (1993). Environmental communication and the contingency of meaning. A research note. In A.Hansol (ED). The Mass media and environmental issues (pp.222-233). Leicester,UK:Leicwster University Press

Daniel Lerner (1958) The Passing of Traditional Society: Modernizing the Middle East. New York: Free Press.

Detjen, J., Fico, F. Li, X. \& Kim, Y. (2000). Changing work environment of environmental reporters. Newspaper Research Journal, 21(1), 211.

Environmental Protection Authority (EPA). 1998. Status of Desertification and implementation of the United Nations plan of Action to combat Desertification New York: .UNEP press

Fahlquist, J.N., (2008). Moral Responsibility for Environmental Problems-Individual or Institutional? J. Agric. Environ. Ethics, DOI 10.1007/s10806-008-9134-5.

- Filho, Walter Leal, Bandeira, Monica Villa. 1995. Media and environmental education. Convergence, Vol.28, Issue 4.

Friedman, S.M. (1991a). Risk management: The public versus the technical Experts. In L. Wilkins \& P. Patterson (Eds.), Risky business: Communicating issues of science, risk, and public policy (pp. 31-41). New York: Greenwood Press.

Friedman, S.M. (1991b). Two decades of the environmental beat. In C.L. LaMay \& E.E. Dennis (Eds.), Media and the environment (pp. 17-28). Washington, D.C.: Island Press

Gaya Tuchman,(1978). Making News: A study in the construction of Reality: New York, Free Press

$>$ Gee, D. (2000). Communicating complexity and uncertainty: A challenge for the media. In J. Smith (Ed.) The daily globe: Environmental change, the public and the media (pp. 208-222). London: Earthscan Publications Ltd.
Greenberg, M.R., Sachsman, D.B., Sandman, P.M., \& Salomone, K.L. (1989). Risk, drama and geography in coverage of environmental risk by network TV. Journalism Quarterly, 66(2), 267276.

Goodfield, J. (19 81). Reflections on science and the media. Washington, DC: American Association for the Advancement of Science.

Hens,L.1996. The Rio conference and thereafter. In B.Nath,L.Hens and D.Devuyst.eds. Sustainable Development Brussels VUB press

Johnstone,J.W.C.(1976). The news people : A sociological portrait of American journalism and their work. Urbana : University of Illinois Press

Jonawitz, M. (1968) The Study of Mass Communication in International Encyclopedia of the Social Sciences, ed. by D.E. Sills, Vol. 3, 41, New York: Macmillan and Free Press

Krasny.M E. and Dillion.J 2013 : Trading zones in environmental education: creating trans transdisciplinary Dialogue.New York: Peter Lang

Kuensel, May, 1999a; BBC news, 2005).the Production of Modernization: Daniel Lerner, Mass Media, and the Passing of Traditional Society. Hemant Shah. Philadelphia: Temple University Press, 2011.

Mazur A, Lee J 1993 Sounding the global alarm: environmental issues in the US national news. Social Stud. Sci.23, 681-720

McComas, K., Shanahan, J., 1999. Telling stories about global climate change: measuring the impact of narratives on issue cycles. Communication Research 26 (1), 30-57.

McDonald, R. (2004) "Television, Materialism and Culture: An Exploration of Imported Media and its Implications for GNH," Journal of Bhutan Studies, Vol. 11, pp. 68-88

McComas, K., Shanahan, J., 1999. Telling stories about global climate change: measuring the impact of narratives on issue cycles. Communication Research 26 (1), 30-57. 
Miller, J., Brown, L., Hill, E., Shellman, A., Ramsing, R. \& Gómez, E. (2010). Measuring the Educational Impact of Promoting Environmental Awareness in Kids (PEAK): the development and implementation of a new scale. In: Proceedings of the 2010 Northeastern Recreation Research Symposium

Nelkin, D. (1995). Selling science: How the press covers science and technology (Rev. ed.). New York: W. H. Freeman.

Novo, M.E. (2003) Alterações Climáticas e seus Impactos nos Recursos Hídricos Subterrâneos em Ilhas (Caso de Estudo: Açores). $2^{\circ}$ Relatório de Progresso. Relatório 112/03-NAS/DHA, Lisboa, LNEC, Maio/2003, 123 pp. (in Portuguese)

Pryor, Larry 1972 "Covering the ecology thicket." The Journal of Environmental Education 4(2):5556.

Rademakers(2004). Examining the handbooks o $n$ environmental journalism: A qualitative docume $n t$ analysis and response to the literature (Unpub lished doctoral dissertation). University of South Florida, Tampa.

Sachsman, D.B. (1999). Commentary: Should reporters use risk as a determinant of environmental coverage? Science Communication, 21(1), 114-121.

Sachsman, D. B. (2006), 'Regional Issues, National Norms: A Four-Region Analysis of US Environment Reporters'. Science Communication, 28, p. 93

Ura, K. (2006) Is Detachment from Media Good? Opinion, Bhutan Observer, 2nd June 2006

Michael Young, 1990. Agricultural policies in industrial contries and their environmental impact

Mukherji, S. (2004) Fragile Environment, New Delhi:

O'Brien, K., 2006. Are we missing the point? Global environmental change as an issue of human security. Global Environmental Change Part A 16 (1), 1-3. O’Connor, R.E., Bord, R.J.,
Fisher, A., 1999. Risk perceptions, general environmental beliefs, and willingness to address climate change. Risk Analysis 19, 461-478

Rockstrom, J., (2009) "Planetary boundaries: Exploring the safe operating space for humanity," Ecology and Society, 14(2), http://www.ecologyandsociety.org/vol14/iss2/ art32 (accessed 09/10/2015)

Sachsman, D.B. (1996). The mass media "discover" the environment: Influences on environmental reporting in the first twenty years. In J.G. Cantrill and C.L. Oravec (Eds.), The symbolic earth (pp. 241-256). Kentucky: The University Press of Kentucky.

Sandman, P.M., Sachsman, D.B. Greenberg, M.R., \& Gochfeld, M. (1987). Environmental risk and the press: An exploratory assessment. New Brunswick: Transaction Bo

Skanavis, C. (2004). Environment and Communication: Having the Right to Choose. Kalidoskopio publishing Company. Athens.

Schoenfeld, C.A. (1980). Newspersons and the environment today. Journalism Quarterly, 57(3), 456-462.

Sellers, Leonard and David W. Jones, Jr. 1973 "Environment and the news media." The Journal of Environmental Education 5(1):51-57.

Singh, S. 2000. Environmental geography. Allahabad: Bhawan publication.

Shukla, P R ( 2001) Macroeconomic models for long term energy and emissions in India, OPSERCH( Special issue on energy ad Environment Moddling (31) 1 Feb.2001

Schoenfeld, Clay 1980 "Ecological conscience in the newsroom: The environment and behavior of environmental reporters." Columbia Journalism Review (forthcoming).

Shukla, R. D. 2001. Teaching of Science and Technology at School Level. School Science, March 2001. New Delhi, National Council of Educational Research and Training, pp. 12-20. 
Smyth, N., (1995). Teaching for a sustainable world: the environmental and development education project for teacher education. Environ. Edu. Res., 1, 21-22.

Skanavis, K. (2004). Environment and Society. Athens: Kaleidoskopio. Mukherji, S. (2004) Fragile Environment, New Delhi: Manak Lowery, S.A. \& DeFleur, M.L. (1988) Milestones in Mass Communication Reasearch: Media Effects, New York and London: Longman

Stocking, H. \& Leonard, J.P. (1990). The greening of the media. Columbia Journalism Review, 29 (December), 37-44.

Trumbo, C., 1996. Constructing climate change: claims and frames in US news coverage of an environmental issue. Public Understanding of Science 5, 269- 283.

Dr. V. K. Narayana Menon (Thrissur Vadakke Kurupath Narayana Menon) (1911 - 1997) was a scholar of classical Indian dance and Indian classical music
United Nations Environment Protection (UNEP). 2007 One planet many people: Atlas of our changing Environment. Nairobi: United Nation reproduction center

Victor Bachetta,(2002). Journalist at Freelance

Weingart, P., Engels, A., Pansegrau, P., 2000. Risks of communication: discourses on climate change in science, politics, and the mass media. Public Understanding of Science 9, 261-283.

Yang, L. (2008). The Role and Ability of the Media to Promote Environmental Awareness; Perspectives from China. Presentation at the 4th Asia-Europe Editor's Roundtable, 22-23 October, Beijing. Available from http://english.cri.cn/2946/2008/10/24/53s417625.h tm. Accessed 26 April 2012.

Wilson, K.M. (2000). Communicating climate change through the media. In S. Allan, B. Adam \& C. Carter (Eds.), Environmental risks and the media, pp. 201-217. London: Routledge.

Witt, William 1974 "The environmental reporter on U.S. daily newspapers." Journalism Quarterly 51(3):697-704. 